\title{
Genomic Analysis Unravels Reduced Inorganic Sulfur Compound Oxidation of Heterotrophic Acidophilic Acidicaldus sp. Strain DX-1
}

\author{
Yuanyuan Liu, ${ }^{1,2}$ Hongying Yang, ${ }^{1}$ Xian Zhang, ${ }^{3}$ Yunhua Xiao, ${ }^{3}$ \\ Xue Guo, ${ }^{3}$ and Xueduan Liu $^{3}$ \\ ${ }^{1}$ School of Materials and Metallurgy, Northeastern University, Shenyang, China \\ ${ }^{2}$ CNMC Luanshya Copper Mines Plc. (CLM), Luanshya, Zambia \\ ${ }^{3}$ School of Minerals Processing and Bioengineering, Central South University, Changsha, China \\ Correspondence should be addressed to Hongying Yang; yanghy@smm.neu.edu.cn
}

Received 14 January 2016; Revised 28 March 2016; Accepted 11 April 2016

Academic Editor: Thomas Lufkin

Copyright (c) 2016 Yuanyuan Liu et al. This is an open access article distributed under the Creative Commons Attribution License, which permits unrestricted use, distribution, and reproduction in any medium, provided the original work is properly cited.

\begin{abstract}
Although reduced inorganic sulfur compound (RISC) oxidation in many chemolithoautotrophic sulfur oxidizers has been investigated in recent years, there is little information about RISC oxidation in heterotrophic acidophiles. In this study, Acidicaldus sp. strain DX-1, a heterotrophic sulfur-oxidizing acidophile, was isolated. Its genome was sequenced and then used for comparative genomics. Furthermore, real-time quantitative PCR was performed to identify the expression of genes involved in the RISC oxidation. Gene encoding thiosulfate: quinone oxidoreductase was present in Acidicaldus sp. strain DX-1, while no candidate genes with significant similarity to tetrathionate hydrolase were found. Additionally, there were genes encoding heterodisulfide reductase complex, which was proposed to play a crucial role in oxidizing cytoplasmic sulfur. Like many heterotrophic sulfur oxidizers, Acidicaldus sp. strain DX-1 had no genes encoding enzymes essential for the direct oxidation of sulfite. An indirect oxidation of sulfite via adenosine- $5^{\prime}$-phosphosulfate was proposed in Acidicaldus strain DX-1. However, compared to other closely related bacteria Acidiphilium cryptum and Acidiphilium multivorum, which harbored the genes encoding Sox system, almost all of these genes were not detected in Acidicaldus sp. strain DX-1. This study might provide some references for the future study of RISC oxidation in heterotrophic sulfur-oxidizing acidophiles.
\end{abstract}

\section{Introduction}

Due to the evolutionary importance and applied perspectives of extreme acidophiles (optimal growth at or below $\mathrm{pH}$ 3.0), researchers have paid much attention to these microorganisms [1-3]. Extreme acidophiles are widely used in the bioprocessing of minerals and bioremediation of acidic and metal-enriched water [4-6]. Many chemolithoautotrophic acidophiles, such as Leptospirillum spp. and Sulfolobus metallicus, can accelerate the dissolution of sulfide minerals by oxidizing ferrous iron or reduced inorganic sulfur compound (RISC) [7]. In addition to obligate autotrophs, many heterotrophic and mixotrophic acidophiles also play key roles in iron and sulfur cycling, such as Ferrimicrobium acidiphilum, Sulfobacillus spp., Thermoplasma sp., and Acidiphilium spp. [7-12].
Species from the Acidicaldus genus are moderately thermophilic and obligate heterotrophic acidophiles within the Alphaproteobacteria class. The type species Acidicaldus organivorans $\mathrm{Y} 008$, which was isolated from a geothermal site in Yellowstone National Park, is a member of facultatively anaerobes and can grow by ferric iron respiration in the anaerobic environment [13]. The closest phylogenetic relatives of Ac. organivorans Y008 are acidophilic heterotrophs, including Acidiphilium [14], Acidisphaera [15], and Acetobacter [16]. Previous studies showed that Acidicaldus organivorus (the synonym of Ac. organivorans) harbored some unique physiological characteristics, which differed from other acidophilic heterotrophs. Compared to Acidisphaera rubrifaciens, which grows at $\mathrm{pH} 4.5-5.0$ and optimal temperature $30-35^{\circ} \mathrm{C}$, Acidicaldus organivorus requires a lower $\mathrm{pH}$ (2.5-3.0) and higher temperature (optima $50-55^{\circ} \mathrm{C}$ ). Ac. 
organivorus can oxidize elemental sulfur to sulfate, though it cannot perform autotrophic growth on sulfur in organicfree media. Additionally, Ac. organivorus can catalyze the dissimilatory reduction of ferric iron, whereas the type strain of As. rubrifaciens does not grow by ferric iron respiration in the absence of oxygen [13].

Although knowledge in the last decade has greatly advanced our understanding on the acidophilic bacteria, it is scarce to attempt to study the physiology and genetics of the heterotrophic sulfur-oxidizing acidophiles. Compared to autotrophic sulfur-oxidizing bacteria, metabolisms of these heterotrophs are more versatile [17]. They can not only use organic matters as energy sources but also obtain energy derived from the oxidation of elemental sulfur or RISC. These traits can confer the heterotrophic sulfur-oxidizing bacteria dual contributions to microbial communities in bioleaching systems: (i) while organic matters inhibit the growth of some facultative autotrophic bacteria $[18,19]$, heterotrophs which can consume the organic matters in the microbial communities might relieve the inhibiting effect of organic matters on the autotrophs; (ii) RISC oxidation would accelerate dissolution of acid soluble metal sulfides. In this study, we chose a strain, isolated from Dexing Copper Mine (Jiangxi, China), to explore its physiologic and genetic properties. The genome sequence of this strain was acquired using the whole genome sequencing and comparative genomics was then performed, aiming to propose its putative RISC oxidation model.

\section{Materials and Methods}

2.1. Isolation and Cultivation of Bacteria. Samples from the surface of effusion pool were inoculated in $9 \mathrm{~K}$ liquid media [20] supplemented with $5 \mathrm{~g} / \mathrm{L}$ elemental sulfur, $4.5 \%$ (w/v) ferrous sulfate, and $0.02 \%$ yeast extract (Oxoid, UK). Strains were purified by repeated single colony (in triplicate) isolation on $9 \mathrm{~K}$ plates solidified with $0.02 \%$ yeast extract and grown at $45^{\circ} \mathrm{C}$ in $9 \mathrm{~K}$ liquid media, $\mathrm{pH} 3.0$, with $0.02 \%$ $(\mathrm{w} / \mathrm{v})$ yeast extract and $10 \mathrm{mM}$ glucose. All procedures were operated aseptically.

\subsection{DNA Extraction, $16 S$ rRNA Gene Amplification, and Phy-} logenetic Analysis. At later exponential phase (generally 4th day), strain DX-1 was harvested by centrifugation $(12,000 \mathrm{~g}$ for $10 \mathrm{~min}$ at $4^{\circ} \mathrm{C}$ ). Genomic DNA was extracted from the pelleted cells using TIANamp Bacteria DNA Kit (Tiangen Biotech, China) according to the manufacturer's instruction and finally was resuspended in TE buffer. 16S rRNA gene sequence was PCR amplified from the genomic DNA extracts of strain DX-1. Amplification was performed in $50 \mu \mathrm{L}$ reaction mixtures containing $1 \mu \mathrm{L}$ of DNA extracts, $1 \mu \mathrm{L}$ each of $10 \mathrm{mM}$ forward and reverse primers, $25 \mu \mathrm{L}$ of universal Taq PCR Master Mix (Tiangen Biotech, China), and $22 \mu \mathrm{L}$ of deionized water. The PCR conditions for amplification were as follows: $94^{\circ} \mathrm{C}$ for $4 \mathrm{~min}$, then 32 cycles of $94^{\circ} \mathrm{C}$ for $30 \mathrm{~s}, 55^{\circ} \mathrm{C}$ for $30 \mathrm{~s}$, and $72^{\circ} \mathrm{C}$ for $45 \mathrm{~s}$, followed by a final extension at $72^{\circ} \mathrm{C}$ for $10 \mathrm{~min}$. PCR product of $16 \mathrm{~S}$ rRNA gene was purified directly with the QIAquick PCR Purification Kit (Qiagen, Germany) and sequenced.
16S rRNA gene sequence of strain DX-1 was aligned with other acidophilic Alphaproteobacteria sequences from the GenBank database using the CLUSTAL program [21]. This alignment was used to make a distance matrix. Phylogenetic trees were constructed using the neighbor joining method by Molecular Evolutionary Genetics Analysis 5.2 (MEGA, version 5.2) [22]. Bootstrap analysis was carried out on 1000 replicate input data sets.

2.3. Genome Sequencing, Assembly, and Annotation. Genomic library construction, sequencing, and assembly were performed according to previous methods [23]. Given the high GC content of genome of Acidicaldus spp., more than $600 \mathrm{Mb}$ pair-ends reads with a depth of over 200fold coverage were obtained. After genome assembly, 375 scaffolds were acquired using SOAPdenovo package [24]. The completeness (95.34\%) of strain DX-1 genome was estimated using the CheckM [25]. Coding sequences (CDSs) were then predicted with the ORF finders Glimmer [26]. All CDSs were annotated by comparison with the public available databases nonredundant NCBI [27] and KEGG [28] using the annotation software BLAST [29]. The unassigned CDSs were further annotated using the HMMPfam program [30]. And the hidden Markov models for the protein domains were obtained from the Pfam database [31]. The software programs tRNAscan-SE and RNAmmer were used for the identifications of tRNA and rRNA, respectively $[32,33]$.

2.4. Comparative Genomics. The genomes of Ap. cryptum JF5 and Ap. multivorum AIU301 were retrieved from the NCBI database. Orthologs between Acidicaldus strain DX-1, Ap. cryptum JF-5, and Ap. multivorum AIU301 were detected via an all-versus-all reciprocal BLASTP search against their own protein sets, respectively [29]. The best sequence similarities were obtained using two cut-off values: $E$-value $\leq 1 e-05$ and minimal coverage by local alignment $=70 \%$.

2.5. RNA Extraction and Real-Time Quantitative PCR Analysis. To investigate the transcript profiles of genes associated with RISC oxidation, Acidicaldus sp. strain DX-1 was cultured at $45^{\circ} \mathrm{C}$ in $9 \mathrm{~K}$ liquid media, $\mathrm{pH} 3.0$ with $0.02 \%(\mathrm{w} / \mathrm{v})$ yeast extract and $10 \mathrm{mM}$ glucose. And the additional $1 \%$ $(\mathrm{w} / \mathrm{v})$ elemental sulfur $\left(\mathrm{S}^{0}\right)$ was added in another group. Microbial cells were harvested at mid-exponential growth phase according to bacterial growth curve. Total RNA was extracted using TRIzol reagent (Invitrogen, Carlsbad, USA), treated with RNase-free DNase I (Qiagen, Valencia, USA) and purified with RNeasy Kit (Qiagen, Valencia, USA). Subsequently, single-stranded cDNA was synthesized with ReverTra Ace qPCR RT Kit (Toyobo, Japan), according to the manufacturer's protocol. The cDNA was stored at $-80^{\circ} \mathrm{C}$, which was used for further RT-qPCR analysis. All experiments under the same conditions were performed in triplicate. The gene expression level with fold change $\geq 1$ were upregulated and otherwise downregulated.

Specific primers targeting selected genes putatively involved in RISC oxidation were designed for real-time PCR analysis (Table 1). The real-time PCR amplification was performed with iCycler iQ Real-Time PCR detection system 
TABLE 1: Primers used for real-time quantitative PCR in this study.

\begin{tabular}{|c|c|c|c|c|}
\hline Targeted gene & Primers & Product size [bp] & Melting temp. $\left[{ }^{\circ} \mathrm{C}\right]$ & Primer sequence \\
\hline$h d r A$ & $\begin{array}{l}\text { Fwd } \\
\text { Rev }\end{array}$ & 262 & 55 & $\begin{array}{l}\text { GCACCGGCTTCACCCATTTC } \\
\text { AGCTGCTCGCGGATCTCCAT }\end{array}$ \\
\hline$h d r B$ & $\begin{array}{l}\text { Fwd } \\
\text { Rev }\end{array}$ & 184 & 55 & $\begin{array}{l}\text { ACTCGACCTGGTATGATTGCTGC } \\
\text { TTGCCGATCCACTGGCTCTT }\end{array}$ \\
\hline$h d r C$ & $\begin{array}{l}\text { Fwd } \\
\text { Rev }\end{array}$ & 161 & 55 & $\begin{array}{l}\text { CACGGCGTGGGAGGTCAATC } \\
\text { CGGCGAGCCAGTCTTCGTAAT } \\
\end{array}$ \\
\hline$h d r B 2$ & $\begin{array}{l}\text { Fwd } \\
\text { Rev }\end{array}$ & 201 & 55 & $\begin{array}{l}\text { ACAACGAACACGCGAAAGAGG } \\
\text { GACGGACGTACATGCAGCCATA }\end{array}$ \\
\hline rhd & $\begin{array}{l}\text { Fwd } \\
\text { Rev }\end{array}$ & 238 & 55 & $\begin{array}{l}\text { CCCAACGAGGGCAAGGACGG } \\
\text { AGAGGCGGAGCAGCCACCAG }\end{array}$ \\
\hline $\operatorname{doxD}$ & $\begin{array}{l}\text { Fwd } \\
\text { Rev }\end{array}$ & 103 & 55 & $\begin{array}{l}\text { CAACTGGATGGCGCACAAA } \\
\text { CGCATAGAGCAGCGGGAAA } \\
\end{array}$ \\
\hline sat & $\begin{array}{l}\text { Fwd } \\
\text { Rev }\end{array}$ & 119 & 55 & $\begin{array}{l}\text { GACCTTCTCGAAAGCCAGAGC } \\
\text { TTGCGGGCAAGCCAAACC }\end{array}$ \\
\hline$s q r$ & $\begin{array}{l}\text { Fwd } \\
\text { Rev }\end{array}$ & 182 & 56 & $\begin{array}{l}\text { CGATTTCGGCGACTCGGGTGT } \\
\text { GCTGGCGGAGTAGGAATTTCTCAT }\end{array}$ \\
\hline$s q r 2$ & $\begin{array}{l}\text { Fwd } \\
\text { Rev }\end{array}$ & 258 & 55 & $\begin{array}{l}\text { AAACCGGGTGCGCTTCGT } \\
\text { TGCGGCTCCTTCGGATTGC }\end{array}$ \\
\hline
\end{tabular}

(Bio-Rad Laboratories Inc., Hercules, USA). $25 \mu \mathrm{L}$ reaction mixtures contained $12.5 \mu \mathrm{L}$ SYBR Green Real-Time PCR Master Mix (Toyobo Co., Ltd., Osaka, Japan), $0.5 \mu \mathrm{L}$ singlestranded cDNA, $1 \mu \mathrm{L}$ each of $10 \mu \mathrm{M}$ forward and reverse primers, and $10 \mu \mathrm{L}$ deionized water. The specific amplification protocol was as follows: $95^{\circ} \mathrm{C}$ for $5 \mathrm{~min}, 40$ cycles of $95^{\circ} \mathrm{C}$ for $20 \mathrm{~s}, 55^{\circ} \mathrm{C}$ for $15 \mathrm{~s}, 72^{\circ} \mathrm{C}$ for $15 \mathrm{~s}$, and a final incubation of $72^{\circ} \mathrm{C}$ for $10 \mathrm{~min}$. The expression of each gene was determined from triplicate reactions in a single real-time PCR amplification. To standardize the quantification of the selected target genes, $16 \mathrm{~S}$ rRNA and glyceraldehyde 3-phosphate dehydrogenase (gapdh) were used as transcription controls to regulate the random and systematic errors. The expressions of selected genes in the medium with $S^{0}$ and without $S^{0}$ were calculated for further analysis.

2.6. Nucleotide Sequence Accession Number. The draft genome sequence of Acidicaldus strain DX-1 has been deposited at DDBJ/EMBL/GenBank under accession number JPYW00000000.

\section{Results and Discussion}

3.1. Isolation and Phylogenetic Analysis. Several strains (named DX-1, DX-5, DX-20, and DX-22) from Dexing Copper Mine sampling sites, which showed similar colony and cellular morphologies, were isolated on solid medium with $0.02 \%$ yeast extract. All of these strains grew as small, white, round to convex-shaped colonies. Considering that $16 \mathrm{~S}$ rRNA sequence analysis showed $100 \%$ sequence identities, only one (strain DX-1) was selected for further analysis. The rooted phylogenetic tree indicated that $16 \mathrm{~S}$ rRNA gene of strain DX1 was assigned into a phyletic cluster with Acidicaldus spp. (Figure 1). Furthermore, 16S rRNA gene of strain DX-1 shared 99\% sequence identity with that of type strain Acidicaldus organivorans Y008 [13], indicating that strain DX-1 belongs to Acidicaldus species.

3.2. Genome Assembly and Annotation. The draft genome sequence of Acidicaldus sp. strain DX-1 contained $2,990,377$ bp with GC content of $68.48 \%$ distributed in 376 scaffolds, which ranged from $1,000 \mathrm{bp}$ to $67,370 \mathrm{bp}$. Given the high sequence coverage (200-fold), it was likely to identify most genes in the draft genome of Acidicaldus sp. strain DX-1. Results showed that genome of Acidicaldus sp. strain DX-1 harbored 3,259 predicted coding sequences (CDSs), which represented $89.83 \%$ of the genome, 1 rRNA operon, and 43 tRNA genes (Table 2). The number of CDSs in this strain was less than that in Acidiphilium multivorum AIU301 but more than that in Acidiphilium cryptum JF-5 and Acetobacter pasteurianus.

3.3. Hydrogen Sulfide Oxidation. Phototrophic bacteria such as Allochromatium vinosum and some Chlorobium spp. can anaerobically oxidize hydrogen sulfide to sulfur via a flavocytochrome $c$-sulfide dehydrogenase [34]. In this process, cytochrome $c_{550}$ is used as electron acceptor for energy production. However, flavocytochrome $c$ in $A$. vinosum is not required for phototrophic growth with hydrogen sulfide. Therefore, sulfide: quinone reductase (SQR) is considered to be essential for growth of $A$. vinosum with hydrogen sulfide. In chemotrophic bacteria, such as some Acidithiobacillus spp., SQR is also responsible for the oxidation of hydrogen sulfide [35]. In Acidicaldus sp. strain DX-1, no candidate genes encoding flavocytochrome $c$-sulfide dehydrogenase were identified, while two genes encoding SQR were found (Table S1, see Supplementary Material available online at http://dx.doi.org/10.1155/2016/8137012). One putative SQR shared $64 \%$ amino acid similarity with that of At. ferrooxidans ATCC 53993, and the other shared 72\% amino acid similarity with that of Bradyrhizobium oligotrophicum S58. Both of 
TABLE 2: General features of Acidicaldus sp. strain DX-1 in comparison with other heterotrophic acidophiles.

\begin{tabular}{|c|c|c|c|c|}
\hline Organism & Acidicaldus sp. strain DX-1 & $\begin{array}{l}\text { Acidiphilium cryptum } \\
\text { JF-5 }\end{array}$ & $\begin{array}{c}\text { Acidiphilium } \\
\text { multivorum AIU301 }\end{array}$ & Acetobacter pasteurianus \\
\hline Isolated from & $\begin{array}{l}\text { Acid effusion of mill } \\
\text { tailing }\end{array}$ & Acidic Sediments & $\begin{array}{l}\text { Pyritic acid mine } \\
\text { drainage }\end{array}$ & $\begin{array}{l}\text { Spontaneous cocoa bean } \\
\text { heap fermentation }\end{array}$ \\
\hline Temperature range & $\begin{array}{l}\text { Moderate thermophilic } \\
\qquad\left(50 \sim 55^{\circ} \mathrm{C}\right)\end{array}$ & Mesophilic $\left(30 \sim 35^{\circ} \mathrm{C}\right)$ & Mesophilic $\left(30-35^{\circ} \mathrm{C}\right)$ & Mesophilic $\left(25-30^{\circ} \mathrm{C}\right)$ \\
\hline $\mathrm{pH}$ range & $2.5-3.0$ & $3.0-3.5$ & $3.0-3.5$ & $5.4-6.3$ \\
\hline Nutrition type & Heterotrophic & Heterotrophic & Heterotrophic & Heterotrophic \\
\hline $\begin{array}{l}\text { Oxygen } \\
\text { requirement }\end{array}$ & Facultatively anaerobic & $\begin{array}{l}\text { Facultatively } \\
\text { anaerobic }\end{array}$ & $\begin{array}{l}\text { Facultatively } \\
\text { anaerobic }\end{array}$ & Obligately aerobic \\
\hline $\mathrm{Fe}$ (III) reduction & Yes & Yes & Yes & No \\
\hline Sulfur oxidation & Yes & No & No & No \\
\hline Genome size $(\mathrm{Mb})$ & 2.99 & 3.39 & 3.75 & 2.91 \\
\hline GC content & $68.48 \%$ & $67.99 \%$ & $67.58 \%$ & $53.04 \%$ \\
\hline $\begin{array}{l}\text { Protein-coding } \\
\text { genes }\end{array}$ & 3259 & 3063 & 3448 & 2875 \\
\hline rRNA operon & 1 & 2 & 2 & 5 \\
\hline Number of tRNAs & 43 & 47 & 48 & 57 \\
\hline
\end{tabular}

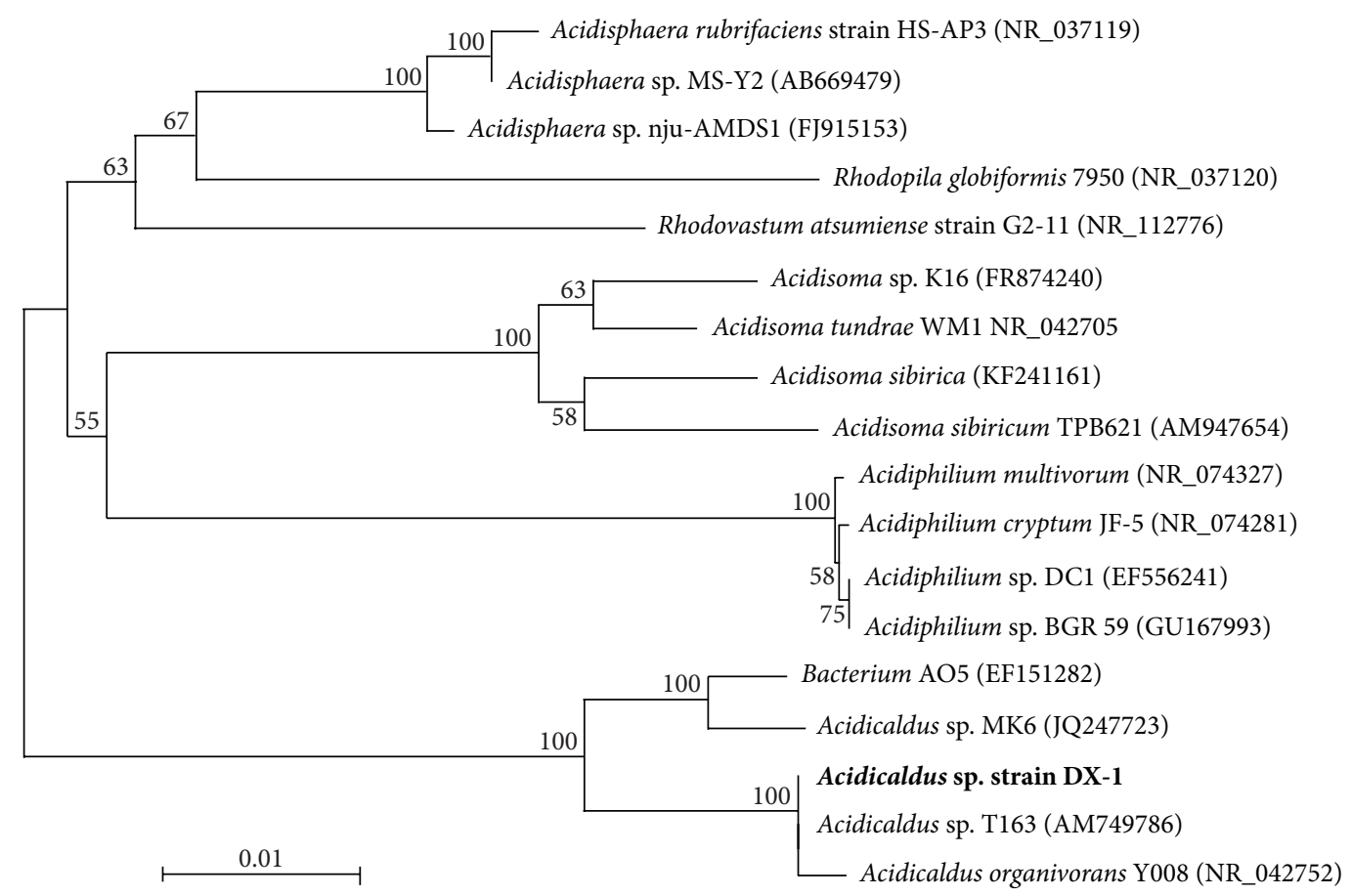

FIGURE 1: Phylogenetic tree of $16 \mathrm{~S}$ rRNA genes showing the relationship of strain DX-1 (in bold) to other acidophilic $\alpha$-Proteobacteria. Phylogenetic tree was constructed based on an alignment of $1283 \mathrm{bp}$ using the neighbor joining method. The scale bar represents 0.01 nucleotide substitutions per 100. And the database accession numbers of the gene sequences used are given in parentheses. Acidisphaera rubrifaciens HS-AP3 was used to root the tree.

them had a small NADH binding domain within a larger FAD binding domain. These results suggested that SQR might be responsible for the oxidation of hydrogen sulfide in Acidicaldus sp. strain DX-1.

3.4. $S_{4} I$ Pathway. In some strains of the genus Acidithiobacillus, the membrane-bound thiosulfate: quinone oxidoreductase (TQO) and tetrathionate hydrolase (TetH) are responsible for the $\mathrm{S}_{4} \mathrm{I}$ pathway $[36,37]$. In At. ferrooxidans, TQO which is constituted of subunits DoxA and DoxD catalyzes the conversion of thiosulfate to tetrathionate, and TetH catalyzes the hydrolysis of tetrathionate to generate sulfur, sulfate and thiosulfate. The consecutive reactions catalyzed by TetH and TQO promote the RISC oxidation in At. ferrooxidans [38]. One ortholog of $d o x D A$ encoding TQO was identified in Acidicaldus sp. strain DX-1, which shared 61\% similarity with that in At. ferrooxidans (Table S1). Further analysis revealed 
that the putative TQO had conserved DoxD domain (Pfam: PF04173) and DoxA domain (Pfam: PF07680). Although previous experiments indicated that Ac. organivorans Y008 can grow on tetrathionate overlay medium [13], no candidate genes with significant similarity to TetH were found in the draft genome of Acidicaldus strain DX-1. Future analyses will be necessary to determine whether TQO indeed catalyzes thiosulfate to tetrathionate and TetH gene is on the portion of the missing draft genome of Acidicaldus sp. strain DX-1.

3.5. Sox Pathway. In the alphaproteobacterium Paracoccus pantotrophus, the periplasmic Sox system encoded by 15 genes [39] are comprised of four subunits, including SoxXA, SoxYZ, SoxB, and Sox $(\mathrm{CD})_{2}$. Each Sox subunit directing its own function was elaborated in previous studies [40]. Both Acidiphilium cryptum and Acidiphilium multivorum have one gene cluster of soxXYZABCD to code for four periplasmic proteins. However, no candidate genes encoding Sox system were identified in the genome of Acidicaldus sp. strain DX1. Considering the Sox system was absent, $\mathrm{S}_{4} \mathrm{I}$ pathway was probably the sole way of further oxidation of thiosulfate in periplasm.

3.6. Sulfur Oxidation. The cytoplasmic sulfur oxygenase reductase (SOR), which mediates biological oxidation of inorganic sulfur, can catalyze the disproportionation reaction of sulfur to generate sulfite, thiosulfate, and hydrogen sulfide $[23,38,40-42]$. Sulfur dioxygenase (SDO) is proposed to be an important elemental sulfur oxidation enzyme in the genus Acidithiobacillus [43], and the relevant gene of SDO and its enzyme activity have been identified in At. caldus [41]. Result showed that the genes sor and sdo were not identified in heterotroph Acidicaldus sp. strain DX-1. Another enzyme directing sulfur oxidation is the cytoplasmic heterodisulfide reductase complex [37], which catalyzes the oxidation of sulfane sulfate (RSSH) to produce sulfite. In At. caldus, RSSH is the product of thio proteins (RSH) with a sulfur atom in the catalysis of thiosulfate by rhodanese (TST) [41]. Results showed that one ortholog of TST was found in Acidicaldus sp. strain DX-1. Additionally, compared to other heterodisulfide reductase complex reported in previous studies [38, 44, 45], only two copies of $h d r B$ gene, one cope of each HdrAC subunit, and $d s r E$ gene were distributed in the draft genome of Acidicaldus sp. strain DX-1 (Table S1). We cannot confirm whether other components were present based on the draft genome alone. The putative HdrA subunit was flavoprotein that contained FAD binding site and conserved residues (C$\mathrm{X}-\mathrm{G}-\mathrm{X}-\mathrm{R}-\mathrm{D}-\mathrm{X}_{6-8}-\mathrm{C}-\mathrm{S}-\mathrm{X}_{2}-\mathrm{C}-\mathrm{C}$ ) for binding of Fe-S cluster, which shared $72 \%$ sequence similarity with that of At. ferrooxidans. Additionally, the putative $\mathrm{HdrB}$ having one typical cysteine-rich regions was distributed in the Hdr gene cluster, and the $\mathrm{HdrC}$ subunit having the $4 \mathrm{Fe}-4 \mathrm{~S}$ ferredoxin iron-sulfur binding domain shared $74 \%$ and $71 \%$ sequence similarities with that of At. ferrooxidans, respectively.

3.7. Sulfite Oxidation. Another important step in the biological RISC oxidation was sulfite oxidation, which was involved in two different pathways. In these models, sulfite was (i) directly oxidized to sulfate, which was catalyzed by a molybdenum-containing sulfite: acceptor oxidoreductase or (ii) indirectly oxidized by the intermediate adenosine- $5^{\prime}$ phosphosulfate (APS) [40]. For indirect sulfite oxidation, sulfite was catalyzed by APS reductase to produce APS and then oxidized to generate sulfate by sulfate adenylyltransferase (SAT). Most studies support the fact that the indirect sulfite oxidation exists in both At. ferrooxidans and At. caldus, which lack gene encoding APS reductase [36, 38]. In Acidicaldus sp. strain DX-1, genes coding for sulfite: acceptor oxidoreductase and APS reductase were not found. However, a putative gene encoding SAT, which has a conservative phosphoadenosine phosphosulfate (PAPS) reductase family domain, was identified in Acidicaldus sp. strain DX-1 (Table S1). Thus, indirect sulfite oxidation might also play an important role in Acidicaldus sp. strain DX-1.

3.8. Terminal Oxidases in RISC Oxidation. In chemolithoautotrophic sulfur-oxidizing bacteria, the RISC oxidation closely links with electron transfer through terminal oxidases. In At. ferrooxidans, electrons from RISC oxidation are transferred via the quinol pool $\left(\mathrm{QH}_{2}\right)$ (i) either directly to terminal oxidase $b d$ or $b o_{3}$ to produce a proton gradient or indirectly through a $b c_{1}$ complex and cytochrome $c$ or a high potential iron-sulfur protein (HiPIP) to $a a_{3}$ oxidase where the concentration of $\mathrm{O}_{2}$ is low or (ii) to NADH complex I to generate reducing power [38]. Genomic analysis showed that Acidicaldus sp. strain DX-1 had one copy of $b d$ ubiquinol oxidase genes $(c y d A B)$, one gene cluster encoding $b c_{1}$ complex, and a gene cluster encoding the $a a_{3}$ oxidase (Table S2). Genes encoding 14 subunits of NADH complex I were also identified in its genome. However, no candidate genes encoding cytochrome $b_{3}$ ubiquinol oxidase were found. Therefore, a putative electron transfer chain in Acidicaldus sp. strain DX-1 was proposed: electrons from SQR, HDR, and TQO were transferred via the $\mathrm{QH}_{2}$ (i) either to $b d$ oxidase or $b c_{1}$ complex to produce the proton gradient or (ii) to NADH complex I to generate reducing power. Additionally, electrons in $b c_{1}$ complex were probably transferred via cytochrome $c$ to the $a a_{3}$ oxidase, where the concentration of $\mathrm{O}_{2}$ is low, to produce the proton gradient.

3.9. Expression of Key Genes Involved in RISC Oxidation. Genomic analysis provided evidence that most genes associated with RISC oxidation in Acidicaldus sp. strain DX-1 were similar to that in other acidophilic sulfur oxidizers. Furthermore, the expressions of relevant genes in both organic matter and organic matter supplemented with sulfur $\left(S^{0}\right)$ medium were validated by real-time quantitative PCR (Figure 2). Results indicated that all selected genes were upregulated in organic matter $+S^{0}$ culture, suggesting that these encoding proteins are likely involved in the RISC oxidation in this strain. Genes encoding TST and three subunits of HdrABC complex for Acidicaldus strain DX-1 were significantly upregulated, while $h d r B 2$ gene has relatively lower expression. The conserved family domains of each $\mathrm{Hdr} \mathrm{ABC}$ subunit and change of gene expression pattern strongly suggested that the HdrABC complex was concluded to oxidize cytoplasmic sulfur in Acidicaldus sp. strain DX1. In particular, genes encoding $\mathrm{Hdr} A B C$ complex were not 


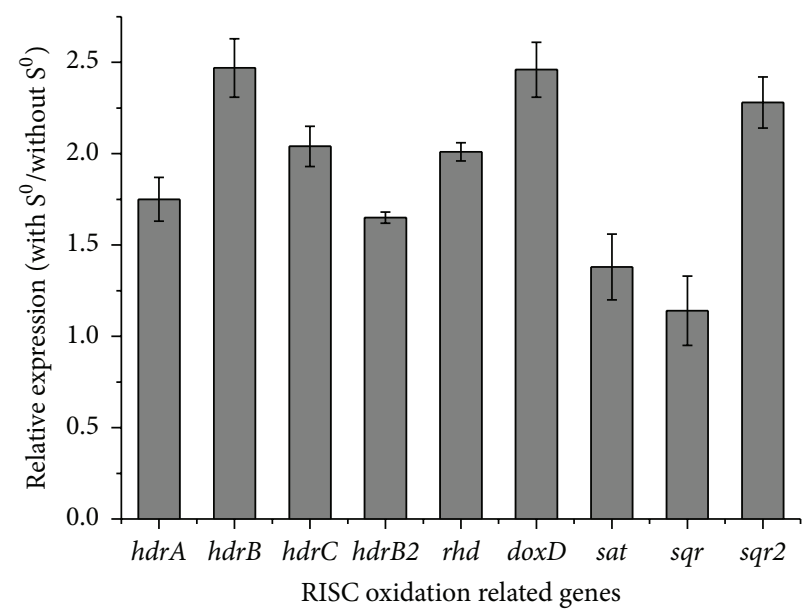

FIGURE 2: RT-qPCR results depicting the expression difference of targeted genes involved in RISC oxidation in Acidicaldus sp. strain DX-1 (in organic matter supplemented with sulfur $\left(S^{0}\right)$ medium or without sulfur). These genes used in this experiment (the encoding proteins and genomic loci are shown in parentheses) include $h d r A$ (pyridine nucleotidedisulfide oxidoreductase; scaffold254: 1-941), $h d r B$ (heterodisulfide reductase subunit B, homolog; scaffold254: 827-2329), $h d r C$ (iron-sulfur cluster-binding protein; scaffold254: 2500-3246), hdrB2 (heterodisulfide reductase subunit B, homolog; scaffold9: 22130-22789), rhd (rhodanese, thiosulfate sulfurtransferase; scaffold153: 15026-15202), doxD (thiosulfate: quinone oxidoreductase; scaffold68: 10659-11696), sat (sulfate adenylyltransferase; scaffold217: 14172-14891), sqr (sulfide quinone reductase; scaffold18: 14834-16117), and sqr2 (sulfide quinone reductase; scaffold92: 4297-5430).

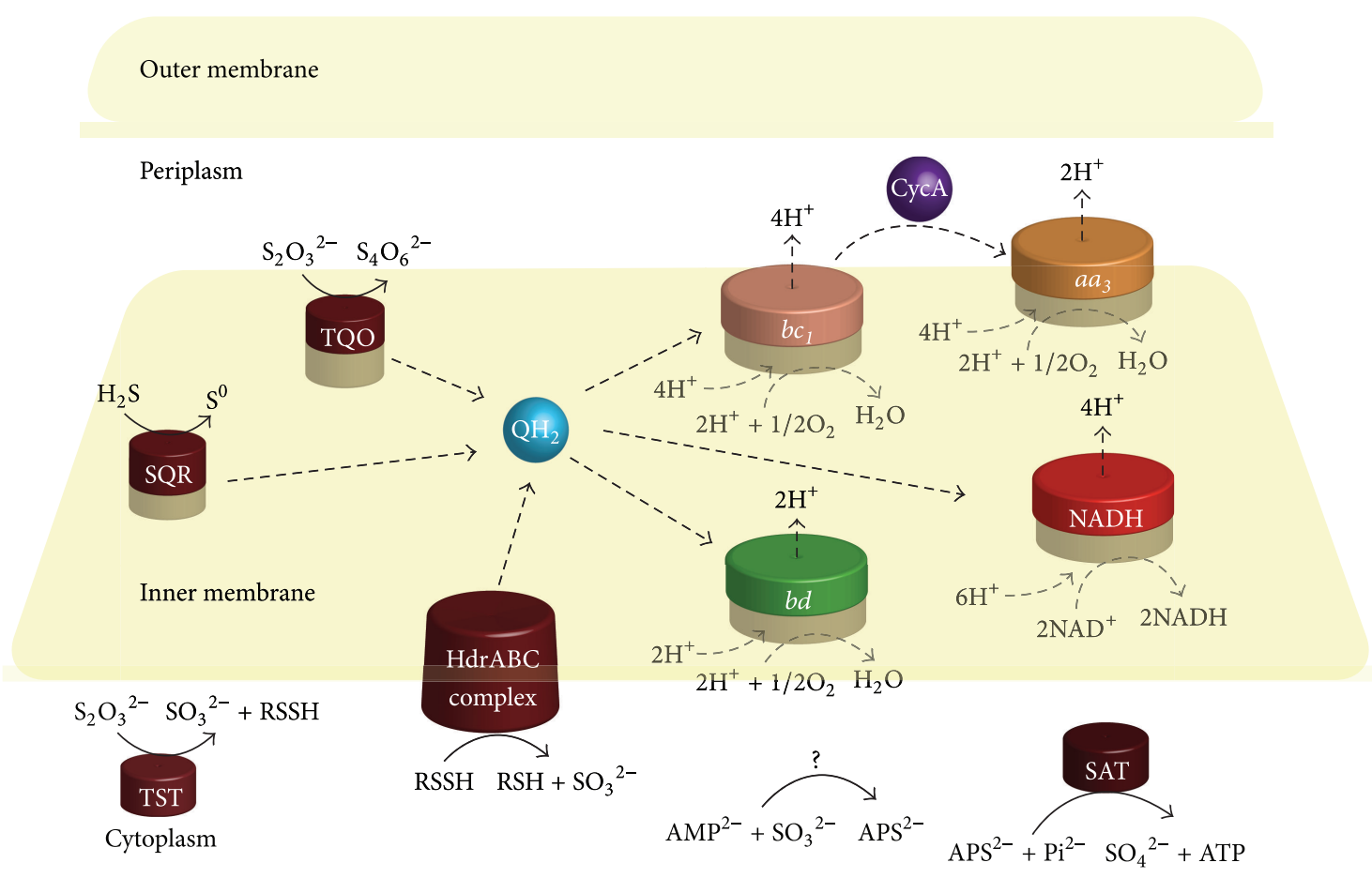

FIGURE 3: Genome-based model of RISC oxidation in Acidicaldus sp. strain DX-1. The figure was adapted from previous sulfur oxidation models [23, 38]. RISC oxidation involves various enzymes and a number of electron carriers. The solid lines denote the oxidation of RISC catalyzed by various enzymes, and the dashed lines denote the direction of electron transfer. SQR, sulfide quinone reductase; TQO, thiosulfate quinone oxidoreductase; TST, rhodanese; HdrABC, heterodisulfide reductase complex; SAT, sulfate adenylyltransferase; $b d$, terminal oxidase $b d ; b c_{1}$, terminal oxidase $b c_{1}$ complex; NADH, NADH complex I; $a a_{3}$, cytochrome $c$ oxidase $a a_{3}$-type; $\mathrm{QH}_{2}$, quinol pool; and CycA, cytochrome $c$. 
found in the closely related bacteria Ap. cryptum JF-5 and Ap. multivorum AIU301, which might be the reason why many strains of Acidiphilium spp. could not directly oxidize sulfur. Additionally, compared with sqr gene, sqr2 gene was significantly upregulated, indicating its importance to metabolize the periplasmic sulfide which might be generated from other unknown metabolic pathways.

\section{Conclusions}

In acidophilic microbial communities, heterotrophic sulfuroxidizing bacteria have versatile functions, which not only can utilize numerous organic matters as energy sources but can also acquire energy from the oxidation of RISC. In this study, we isolated a heterotrophic sulfur-oxidizing bacterium, Acidicaldus sp. strain DX-1, from the effusion of mill tailings in Dexing Copper Mine. Comparative genomics and RT-qPCR analysis revealed that several genes associated with RISC oxidation in Acidicaldus sp. strain DX-1 were similar to other acidophilic sulfur-oxidizing bacteria. Based on the aforementioned analyses, a model for RISC oxidation in Acidicaldus sp. strain DX-1 was hypothesized (Figure 3), which might provide new insights and guides for the RISC oxidation of heterotrophs in the future.

\section{Competing Interests}

The authors declare that there is no conflict of interests regarding the publication of this paper.

\section{Acknowledgments}

The authors would like to thank Dr. Yili Liang in Central South University for proofreading the paper.

\section{References}

[1] M. Dopson and D. B. Johnson, "Biodiversity, metabolism and applications of acidophilic sulfur-metabolizing microorganisms," Environmental Microbiology, vol. 14, no. 10, pp. 26202631, 2012.

[2] C. Baker-Austin and M. Dopson, "Life in acid: pH homeostasis in acidophiles," Trends in Microbiology, vol. 15, no. 4, pp. 165$171,2007$.

[3] J. P. Cárdenas, J. Valdés, R. Quatrini, F. Duarte, and D. S. Holmes, "Lessons from the genomes of extremely acidophilic bacteria and archaea with special emphasis on bioleaching microorganisms," Applied Microbiology and Biotechnology, vol. 88, no. 3, pp. 605-620, 2010.

[4] D. B. Johnson, M.-A. Dziurla, Å. Kolmert, and K. B. Hallberg, "The microbiology of acid mine drainage: genesis and biotreatment: review article," South African Journal of Science, vol. 98, no. 5-6, pp. 249-255, 2002.

[5] X. Zhang, J. Niu, Y. Liang, X. Liu, and H. Yin, "Metagenomescale analysis yields insights into the structure and function of microbial communities in a copper bioleaching heap," $B M C$ Genetics, vol. 17, no. 1, article 21, 2016.

[6] Y. Xiao, Y. Xu, W. Dong et al., "The complicated substrates enhance the microbial diversity and zinc leaching efficiency in sphalerite bioleaching system," Applied Microbiology and Biotechnology, vol. 99, no. 23, pp. 10311-10322, 2015.

[7] K. B. Hallberg and D. B. Johnson, "Biodiversity of acidophilic prokaryotes," Advances in Applied Microbiology, vol. 49, pp. 37$84,2001$.

[8] D. B. Johnson, P. Bacelar-Nicolau, N. Okibe, A. Thomas, and K. B. Hallberg, "Ferrimicrobium acidiphilum gen. nov., sp. nov. and Ferrithrix thermotolerans gen. nov., sp. nov.: heterotrophic, ironoxidizing, extremely acidophilic actinobacteria," International Journal of Systematic and Evolutionary Microbiology, vol. 59, no. 5, pp. 1082-1089, 2009.

[9] H. R. Watling, F. A. Perrot, and D. W. Shiers, "Comparison of selected characteristics of Sulfobacillus species and review of their occurrence in acidic and bioleaching environments," Hydrometallurgy, vol. 93, no. 1-2, pp. 57-65, 2008.

[10] A. Segerer, T. A. Langworthy, and K. O. Stetter, "Thermoplasma acidophilum and Thermoplasma volcanium sp. nov. from Solfatara fields," Systematic and Applied Microbiology, vol. 10, no. 2, pp. 161-171, 1988.

[11] D. B. Johnson and T. A. M. Bridge, "Reduction of ferric iron by acidophilic heterotrophic bacteria: evidence for constitutive and inducible enzyme systems in Acidiphilium spp.," Journal of Applied Microbiology, vol. 92, no. 2, pp. 315-321, 2002.

[12] R. Guay and M. Silver, "Thiobacillus acidophilus sp. nov.; isolation and some physiological characteristics," Canadian Journal of Microbiology, vol. 21, no. 3, pp. 281-288, 1975.

[13] D. B. Johnson, B. Stallwood, S. Kimura, and K. B. Hallberg, "Isolation and characterization of Acidicaldus organivorus, gen. nov., sp. nov.: a novel sulfur-oxidizing, ferric iron-reducing thermo-acidophilic heterotrophic Proteobacterium," Archives of Microbiology, vol. 185, no. 3, pp. 212-221, 2006.

[14] A. P. Harrison, "Acidiphilium cryptum gen. nov., sp. nov., heterotrophic bacterium from acidic mineral environments," International Journal of Systematic Bacteriology, vol. 31, pp. 327332, 1981.

[15] A. Hiraishi, Y. Matsuzawa, T. Kanbe, and N. Wakao, "Acidisphaera rubrifaciens gen. nov., sp. nov., an aerobic bacteriochlorophyll-containing bacterium isolated from acidic environments," International Journal of Systematic and Evolutionary Microbiology, vol. 50, no. 4, pp. 1539-1546, 2000.

[16] Y. Azuma, A. Hosoyama, M. Matsutani et al., "Whole-genome analyses reveal genetic instability of Acetobacter pasteurianus," Nucleic Acids Research, vol. 37, no. 17, pp. 5768-5783, 2009.

[17] D. B. Johnson and F. F. Roberto, "Heterotrophic acidophiles and their roles in the bioleaching of sulfide minerals," in Biomining: Theory, Microbes and Industrial Processes, Biotechnology Intelligence Unit, pp. 259-279, Springer, Berlin, Germany, 1997.

[18] Q. Li, Y. Tian, X. Fu et al., "The community dynamics of major bioleaching microorganisms during chalcopyrite leaching under the effect of organics," Current Microbiology, vol. 63, no. 2, pp. 164-172, 2011.

[19] J. Peng, R. Zhang, Q. Zhang, L. Zhang, and H. Zhou, "Screening and characterization of Acidiphilium sp. PJH and its role in bioleaching," Transactions of Nonferrous Metals Society of China, vol. 18, no. 6, pp. 1443-1449, 2008.

[20] N. P. Marhual, N. Pradhan, R. N. Kar, L. B. Sukla, and B. K. Mishra, "Differential bioleaching of copper by mesophilic and moderately thermophilic acidophilic consortium enriched from same copper mine water sample," Bioresource Technology, vol. 99, no. 17, pp. 8331-8336, 2008.

[21] J. D. Thompson, T. J. Gibson, F. Plewniak, F. Jeanmougin, and D. G. Higgins, "The CLUSTAL X windows interface: flexible 
strategies for multiple sequence alignment aided by quality analysis tools," Nucleic Acids Research, vol. 25, no. 24, pp. 48764882, 1997.

[22] K. Tamura, D. Peterson, N. Peterson, G. Stecher, M. Nei, and S. Kumar, "MEGA5: molecular evolutionary genetics analysis using maximum likelihood, evolutionary distance, and maximum parsimony methods," Molecular Biology and Evolution, vol. 28, no. 10, pp. 2731-2739, 2011.

[23] H. Yin, X. Zhang, X. Li et al., "Whole-genome sequencing reveals novel insights into sulfur oxidation in the extremophile Acidithiobacillus thiooxidans," BMC Microbiology, vol. 14, no. 1, article 179, 2014.

[24] R. Luo, B. Liu, Y. Xie et al., "SOAPdenovo2: an empirically improved memory-efficient short-read de novo assembler," GigaScience, vol. 1, article 18, 2012.

[25] D. H. Parks, M. Imelfort, C. T. Skennerton, P. Hugenholtz, and G. W. Tyson, "CheckM: assessing the quality of microbial genomes recovered from isolates, single cells, and metagenomes," Genome Research, vol. 25, no. 7, pp. 1043-1055, 2015.

[26] A. L. Delcher, K. A. Bratke, E. C. Powers, and S. L. Salzberg, "Identifying bacterial genes and endosymbiont DNA with Glimmer," Bioinformatics, vol. 23, no. 6, pp. 673-679, 2007.

[27] D. L. Wheeler, T. Barrett, D. A. Benson et al., "Database resources of the national center for biotechnology information," Nucleic Acids Research, vol. 35, no. 1, pp. D5-D12, 2007.

[28] M. Kanehisa and S. Goto, "KEGG: kyoto encyclopedia of genes and genomes," Nucleic Acids Research, vol. 28, no. 1, pp. 27-30, 2000.

[29] S. F. Altschul, T. L. Madden, A. A. Schäffer et al., "Gapped BLAST and PSI-BLAST: a new generation of protein database search programs," Nucleic Acids Research, vol. 25, no. 17, pp. 3389-3402, 1997.

[30] R. D. Finn, J. Tate, J. Mistry et al., "The Pfam protein families database," Nucleic Acids Research, vol. 36, no. 1, pp. D281-D288, 2008.

[31] A. Bateman, L. Coin, R. Durbin et al., "The Pfam protein families database," Nucleic Acids Research, vol. 32, pp. D138D141, 2004.

[32] T. M. Lowe and S. R. Eddy, "tRNAscan-SE: a program for improved detection of transfer RNA genes in genomic sequence," Nucleic Acids Research, vol. 25, no. 5, pp. 955-964, 1997.

[33] K. Lagesen, P. Hallin, E. A. Rødland, H.-H. Stærfeldt, T. Rognes, and D. W. Ussery, "RNAmmer: consistent and rapid annotation of ribosomal RNA genes," Nucleic Acids Research, vol. 35, no. 9, pp. 3100-3108, 2007.

[34] J. M. Visser, G. A. H. De Jong, L. A. Robertson, and J. G. Kuenen, "A novel membrane-bound flavocytochrome c sulfide dehydrogenase from the colourless sulfur bacterium Thiobacillus sp. W5," Archives of Microbiology, vol. 167, no. 5, pp. 295-301, 1997.

[35] S. Wakai, M. Tsujita, M. Kikumoto, M. A. Manchur, T. Kanao, and K. Kamimura, "Purification and characterization of sulfide:quinone oxidoreductase from an acidophilic ironoxidizing bacterium, Acidithiobacillus ferrooxidans," Bioscience, Biotechnology and Biochemistry, vol. 71, no. 11, pp. 2735-2742, 2007.

[36] S. Mangold, J. Valdés, D. S. Holmes, and M. Dopson, "Sulfur metabolism in the extreme acidophile acidithiobacillus caldus," Frontiers in Microbiology, vol. 2, article 17, 2011.

[37] J. Valdés, I. Pedroso, R. Quatrini et al., "Acidithiobacillus ferrooxidans metabolism: from genome sequence to industrial applications," BMC Genomics, vol. 9, no. 1, article 597, 2008.
[38] R. Quatrini, C. Appia-Ayme, Y. Denis, E. Jedlicki, D. S. Holmes, and V. Bonnefoy, "Extending the models for iron and sulfur oxidation in the extreme acidophile Acidithiobacillus ferrooxidans," BMC Genomics, vol. 10, article 394, 2009.

[39] C. G. Friedrich, F. Bardischewsky, D. Rother, A. Quentmeier, and J. Fischer, "Prokaryotic sulfur oxidation," Current Opinion in Microbiology, vol. 8, no. 3, pp. 253-259, 2005.

[40] C. G. Friedrich, D. Rother, F. Bardischewsky, A. Ouentmeier, and J. Fischer, "Oxidation of reduced inorganic sulfur compounds by bacteria: emergence of a common mechanism?" Applied and Environmental Microbiology, vol. 67, no. 7, pp. 28732882, 2001.

[41] L. Chen, Y. Ren, J. Lin, X. Liu, X. Pang, and J. Lin, "Acidithiobacillus caldus sulfur oxidation model based on transcriptome analysis between the wild type and sulfur oxygenase reductase defective mutant," PLoS ONE, vol. 7, no. 9, Article ID e39470, 2012.

[42] M. Liljeqvist, O. I. Rzhepishevska, and M. Dopson, "Gene identification and substrate regulation provide insights into sulfur accumulation during bioleaching with the psychrotolerant acidophile Acidithiobacillus ferrivorans," Applied and Environmental Microbiology, vol. 79, no. 3, pp. 951-957, 2013.

[43] P. Ramírez, N. Guiliani, L. Valenzuela, S. Beard, and C. A. Jerez, "Differential protein expression during growth of Acidithiobacillus ferooxidans on ferrous iron, sulfur compounds, or metal sulfides," Applied and Environmental Microbiology, vol. 70, no. 8, pp. 4491-4498, 2004.

[44] L.-J. Liu, Y. Stockdreher, T. Koch et al., "Thiosulfate transfer mediated by DsrE/TusA homologs from acidothermophilic sulfur-oxidizing archaeon Metallosphaera cuprina," The Journal of Biological Chemistry, vol. 289, no. 39, pp. 26949-26959, 2014.

[45] Y. Stockdreher, S. S. Venceslau, M. Josten, H.-G. Sahl, I. A. C. Pereira, and C. Dahl, "Cytoplasmic sulfurtransferases in the purple sulfur bacterium Allochromatium vinosum: evidence for sulfur transfer from DsrEFH to DsrC," PLoS ONE, vol. 7, no. 7, Article ID e40785, 2012. 

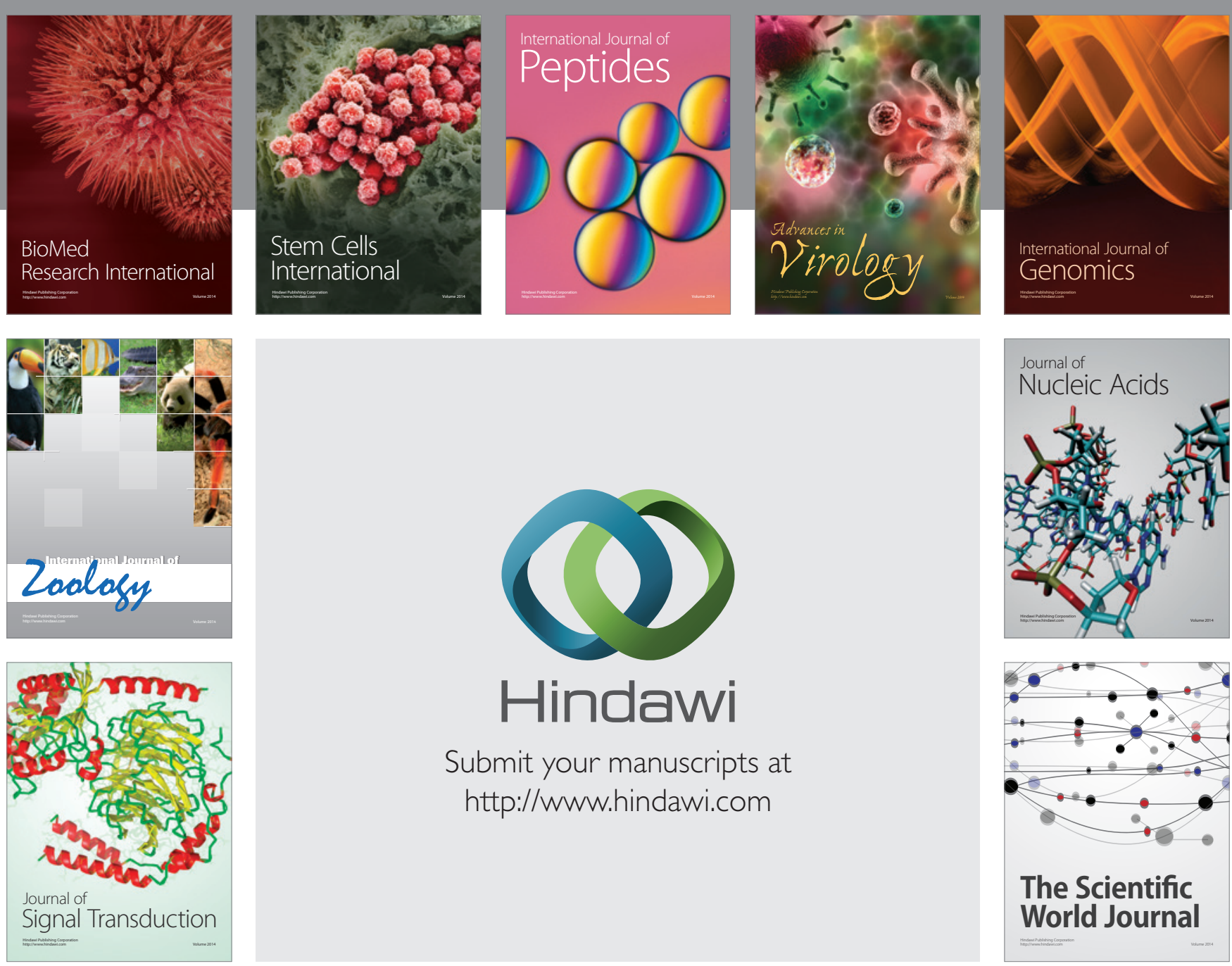

Submit your manuscripts at

http://www.hindawi.com
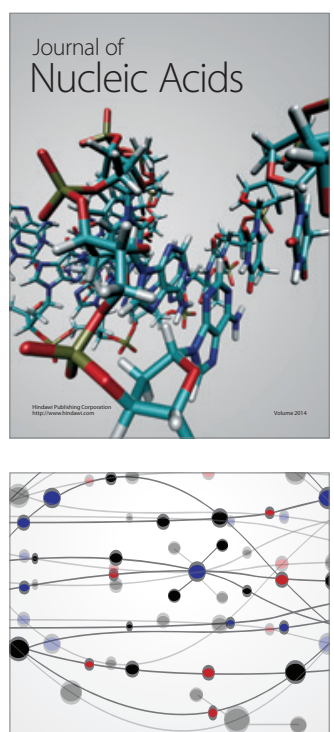

The Scientific World Journal
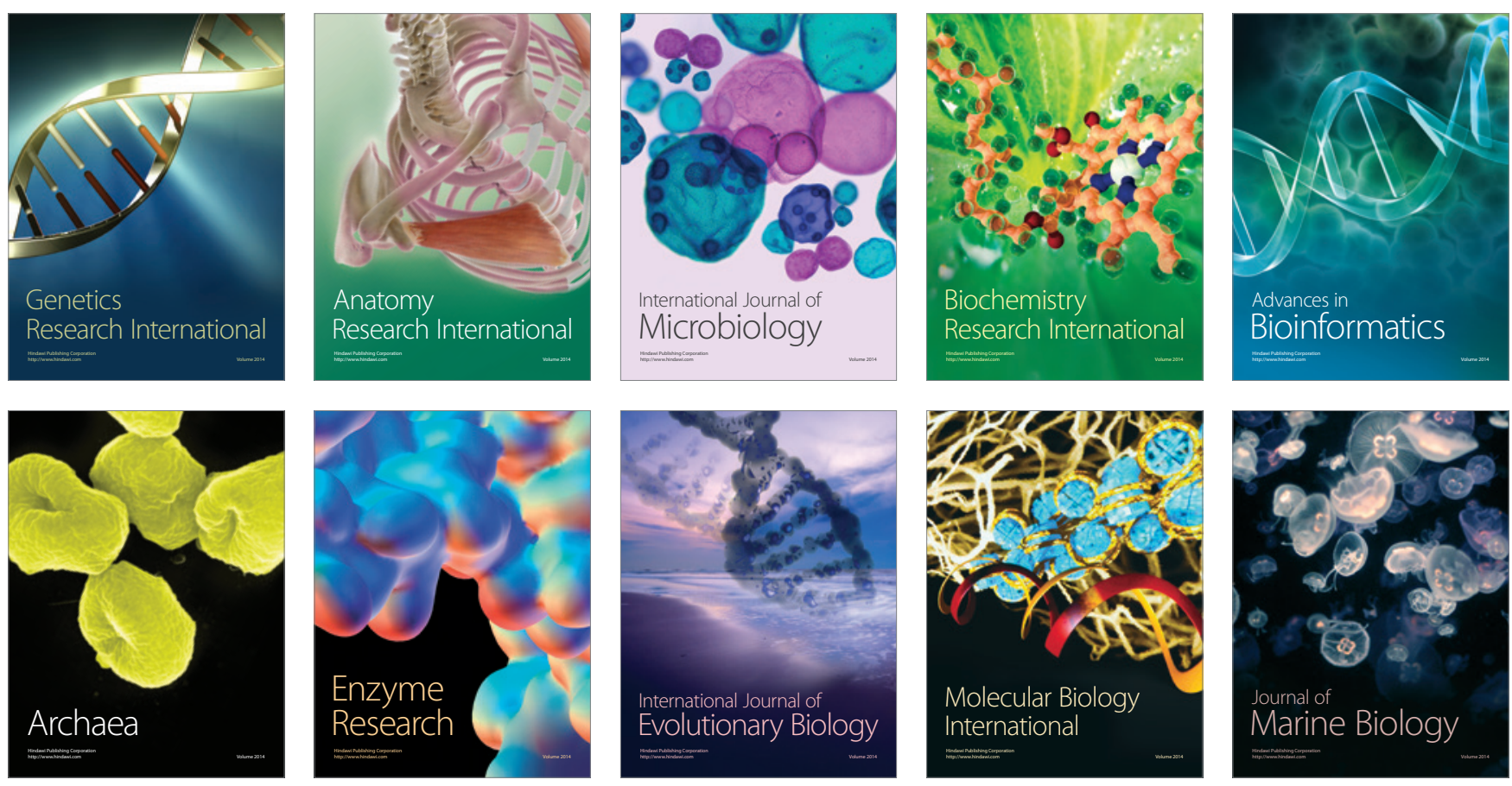